\title{
Translation as a Pedagogical Device for Improving Students' Reading Comprehension in the ESP text
}

\author{
Lia Novita ${ }^{1}$, Bachrudin Mustafha $^{2}$ \\ \{lienovitza@yahoo.co.id $\left.{ }^{1}\right\}$ \\ Indonesia Institute of Education (IPI) Garut, West Java - Indonesia ${ }^{1}$, Indonesia University of \\ Education (UPI) Bandung, West Java - Indonesia ${ }^{2}$
}

\begin{abstract}
Most students are difficult to understand the meaning of the ESP texts because they should think about different discourses and practices that have valued in different content fields. To make students able to understand the reading comprehension of the ESP texts, translation should be used as a pedagogical device. Therefore, the objectives of this study were to measure whether or not translation as a pedagogical device has any significant impact for improving students' reading comprehension in the ESP texts and to investigate what kind of experience the students get from learning translation as a pedagogical device for improving their reading comprehension in the ESP texts. This study used an experimental study research design which employed sequential explanatory mixed-method - quantitative followed by qualitative. Pre-test and post-test were used in quantitative stage; whereas, questionnaire was used in qualitative stage. The quantitative data were analyzed through paired sample t-test to analyze pre-test and posttest of experiment group, and independent sample t-test was used to analyze the post-test score of both experimental group and control group; whereas, the qualitative data were analyzed through codification and categorization. The study revealed two findings related to two research questions. First, the result of quantitative manual and SPSS calculation by using paired sample t-test resulted 9.83 which was then consulted with table t 0.05 with the degree of freedom 26 which is 2.056 . The results of the consultation show that the price of $t$ is greater than the table of 9.83>2.056. According to the measurement results using the effectiveness table, the use of Translation as a pedagogical tool is effective to be applied to the teaching of Reading ESP text because there is an increase in student learning outcomes before and after the technique is applied. Then, there are three types of student experience in understanding ESP reading texts using Translation (translation), namely (1) identification of main ideas, (2) making inferences, (3) recognizing paragraph patterns. These three types of experience will determine the accuracy of their ESP reading text comprehension.
\end{abstract}

Keywords: Translation, Reading comprehension, ESP texts.

\section{Introduction}

Most students are difficult to read and understand the meaning of the ESP texts because they should think about different discourses and practices that have valued in different content fields. They experience a great difficulty in reading and understanding the English text in ESP. To make students easy to understand the reading comprehension of the ESP texts, translation shoud be used as a pedagogical device. Translation can help the students improve the skill of reading, writing, speaking and listening. In reading comprehension of the ESP texts, 
translation is needed as a device for understanding the meaning. Translation is a teaching device that can help students to understand and use the target language more clearly and accurately [1]. Then, translation as a pedagogical tool can be successfully employed at any level of proficiency, at school or university, as a valuable and creative teaching aid to support, integrate, and strengthen the four language skills. Although translation is recommended to be used as a means only and not as an end, it is strongly advised that it is used as an end for Specific Purposes. In other words, as much as translation should be an essential activity in ESP [2],[3].

Therefore, the objective of this study were to measure whether or not translation as a pedagogical device has any significant impact for improving students' reading comprehension in the ESP texts and to investigate what kind of experience the students get from learning translation as a pedagogical device for improving their reading comprehension in the ESP texts.To support this study, there are some theoretical foundations. Translation as a pedagogical device gives some advantages for more specialized communication. First, translation can assist the students to have information transfer, it can be employed as a pedagogic procedure. Translation provides an opportunity to relate students' own knowledge to the acquisition of English as a foreign language [4]. Translation, in this effect, should take into consideration the already existed knowledge. Second, translation can help the learner to clarify meaning. It is now seen to be a positive teaching/ learning resource. Third, through translation, the students deepen their understanding of two languages and two cultures and enhance their knowledge of structure. Those advantages can be used in transferring meanings and conveying messages of reading comprehension in ESP because the nature of ESP focuses on discourse analysis from the early register to genre analysis in different content fields. ESP has specialized subject areas, the topics, terminology methodology, different forms of language and different purposes of communication [5].

In this case, the writer starts the study by concerning and identifying various previous studies and discussions regarding translation as a pedagogical device and its relation to understanding reading comprehension in ESP. The research about the role of translation in promoting reading comprehension of Iranian High School Students and the purpose of this study was to see whether translation had any significant impact on promoting reading comprehension of Iranian high school students [1]. The finding was that translation as an ELT technique has a significant effect on promoting reading comprehension of Iranian high school students. Then, Translation in EFL classes as L2 learning practice and the study concludes that translation tasks could promote learners' receptive skills and productive skills.

Based on the burning issue above, this study focused on translation as a pedagogical device for improving students' reading comprehension in the ESP texts. The result of the study is expected to inspire the teachers in using translation for teaching reading comprehension of the ESP texts.

\section{Method of the Study}

\subsection{Research Design}

The study used explanatory sequential mixed methods. The researcher used a quantitative study as the first method, and then it is followed by qualitative method as the second method. For quantitative method, this study used experimental design because it uses two groups 
consists of the experimental group and the control group. For qualitative method, this study used questionnaire.

\subsection{Site and Participants}

In order to meet the purpose of the study, the researcher chose the most appropriate site and participant, as purposeful sampling. The purposive site for this study is a university located in Tarogong in kabupaten Garut.

The participant is the students of fourth semester of the ESP class in English education program. Similar to the previous reason, this consideration purposively gives the researcher boundless time and place to conduct research without having any troubles. The fourth semester students in this program were four classes.

\subsection{Data Processing}

Data processing consists of three stages which include data collection, data analysis, and data interpretation. Those three stages were conducted both on quantitative session and qualitative session.

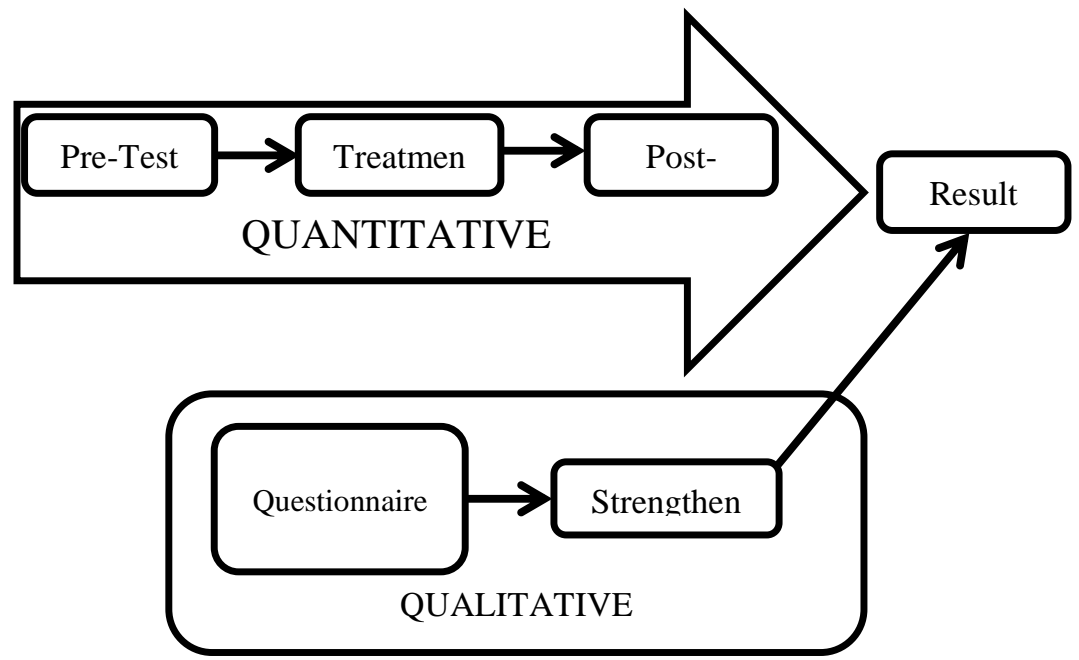

Fig 1 Conceptual Framework 1 (Cresswel,2014)

\subsubsection{Quantitative Stage}

The quantitative session involved pre-test and post-test to both experimental group and control group. Between pre-test and post-test, both experiment and control group are given treatment

\subsubsection{Data Collection in Quantitative Stage (Pre-Test and Post-Test)}

Data collection in quantitative session involved pre-test and post-test as a measurement. The pre-test and post-test is a test of reading comprehension of the ESP texts. The texts will be different but in the same weight in term of three things, fidelity, liberty, and equivalence. The 
writer interprets that the meaning of being faithful here is that the text relevant to the participant, as class (I) and (II) are given a text discussing the ESP texts. Therefore, there is no problem to give different text and questions to different group/class because those texts also meet the discussion to their major, the ESP subject.

The next criterion that Nord mentioned is the liberty which means being free. The writer himself sees that the term being free is that the text is not too over-discussed or over-laps in its discussion, and the language to discuss the matter of ESP context. It is in an understandable language for the ESP class students, thus they understand freely the text because the text is their major of discussion.

Finally, the last criterion is the equivalence. Nord mentions that the term equivalence here means that two texts share the same function. The writer chose the texts which have the same function related to the ESP texts.During the test, the students analyzed text above individually and then tried to interpret the meaning through answering the questions of the text. The total amount of time given to interpret the text is 50 minutes ( 1 credit hour for university). While understanding the text, students were allowed to consult dictionary whether it is physical dictionary (dictionary book) or electronic dictionary (phone dictionary). The main output that the students insisted to understand and answer the questions.

\subsubsection{Scoring for Pre-test and Post-test}

The test is focused on extensive reading, so before examining a few tasks that have proved to be useful in assessing extensive reading, it is essential to note that a number of the tasks described in previous categories can apply here. Among them are impromptu reading plus comprehension questions, short - answer tasks, editing, scanning, ordering, information transfer and interpretation. In assessing extensive reading is the technique of asking a student to respond to a text. Scoring is difficult because of the subjectivity of determining an accurate reflection of the article itself. follows:

For the reading component of the task, a holistic scoring system may be feasible as

\begin{tabular}{|c|l|}
\hline 3 & $\begin{array}{l}\text { Demonstrate clear, unambiguous comprehension of the main and supporting } \\
\text { ideas. }\end{array}$ \\
& $\begin{array}{l}\text { Demonstrate comprehension of the main idea but lacks comprehension of some } \\
\text { supporting ideas }\end{array}$ \\
1 & Demonstrates only a partial comprehension of the main ideas. \\
0 & Demonstrate no comprehension of the main and supporting ideas.
\end{tabular}

Fig. 3.3. Holistic scoring scale for summarizing and responding to reading

\subsubsection{Treatment}

After the pre-test and before the post-test, there is a treatment for experimental group. The treatment here means the teaching and learning conducted in experimental group is involving translation as a pedagogical device. The treatment will be done for seven meetings.

\subsubsection{Quantitative Data Analysis and Result}


The data taken from the pre-test and the post-test is the score reflecting the students' ability. This data will be analyzed by using t-test only on post-test. The consideration of using t-test is that t-test is used to measure or can be conducted on a one sample, paired samples, and independent samples. The sample used on this study is two samples where there are two groups which are equal but given different treatment on each group to measure whether or not there is difference.

The quantitative session will be analyzed through t-test procedure. The result of post-test is analyzed through stages as follow:

In order to analyze the quantitative data, the researcher chose t-test procedure which includes two t-test design, they are the paired sample t-test and the independent t-test. The paired sample t-test used to analyze the progress of the experimental group, whereas the independent t-test used to measure those experimental and control group post-test score.

\subsubsection{Qualitative Stage}

After the result of the quantitative session is acquired, the qualitative procedure is conducted in order to strengthen the result in the quantitative session. The result whether using translation as a pedagogical device gives significant change to the student score is strengthened by the answer of the student qualitatively.

\subsubsection{Qualitative Data Collection}

The data in qualitative session was conducted just only through one instrument questionnaire. The qualitative session was conducted just to take any possible reason of the quantitative session without any further and elaborated discussion. However it was be slightly discussed to take any relation and to describe the score taken from quantitative session. Questionnaire in this study was used to know the student experience through an arranged set of closed and opened question. This questionnaire was spreaded among the discussion about how the students' perspective and experience toward the practice of translation as a pedagogical device for their reading comprehension in the ESP texts.

\subsubsection{Qualitative Data Analysis and Interpretation}

The data collected through questionnaire was processed through several stages of process. These processes included the first was the coding and then categorization for later interpretation. Sometimes the analysis of qualitative data is only briefly covered through coding and the generation of theory from data.

\section{Finding And Discussion}

\subsection{Significant Impact of Student Reading Comprehension in ESP Text through Translation}

Based on the results of the $t$ test that has been done, the price of $t$ obtained 9.83 which was then consulted with table t 0.05 with the degree of freedom 26 which is 2.056 . The results of the consultation show that the price of $t$ is greater than the table of 9.83>2.056. According to the measurement results using the effectiveness table, the use of Translation as a 
pedagogical tool is effective to be applied to the teaching of Reading ESP text because there is an increase in student learning outcomes before and after the technique is applied.

\subsection{Student Perception in Reading Learning ESP Text by Using Translation as a Pedagogical Device}

This section discussed the data obtained from the questionnaire given to students. In general the students responded positively to the role / strategy of the Lecturer in teaching Reading ESP text using Translation (translation). Their perception can be categorized into low level associations. This means that students who have low knowledge will need direct instruction directives in the concept. However, they have understood the lecturers' questions. On the contrary for students who already have a lot of knowledge, they will need the guidance of the lecturer but may be able to work on certain reading texts. So that it can be suggested that the Reading ESP text teaching strategy by using translation used depend on the adequacy of previous student knowledge.

There are three types of student experience in understanding ESP reading texts using Translation (translation), namely (1) identification of main ideas, (2) making inferences, (3) recognizing paragraph patterns. These three types of experience will determine the accuracy of their ESP reading text comprehension. (1). Identifying the main ideas, will tend to lead students to take a buttom-up reading strategy such as reading sentences per sentence, rereading, translating, recognizing hyphens, and of course using a dictionary to find the main idea of an ESP reading text. Usually the level of accuracy of the results of analyzing them is relatively low. Nearly $50 \%$ of students can accurately identify key ideas by using translation strategies and reading sentences per sentence. $28 \%$ have been able to recognize the hyphenation of the sentence as an interactive strategy and only $12 \%$ of students can identify the main idea accurately by using learning strategies to read sentences per sentence. (2) Typical reading to draw conclusions. They tell that they use a butt-up reading strategy, among others through reading sentences per sentence, rereading, translating, paraphrasing, and using cohesive signs of discourse. From the analysis of questionnaires that have been distributed to students, $30 \%$ of them are able to make conclusions accurately. But when using the cohesive sign of an ESP discourse nearly $70 \%$ of students are able to make conclusions accurately. (3) When viewed from the type of student strategy in reading Reading ESP text using Translation (translation), 25\% of them are able to correctly recognize the organization of paragraphs through paraphrasing, rereading or translating. While nearly $75 \%$ of students use cohesive text to recognize the organization of a paragraph.

\section{Conclusion}

The use of translation as a pedagogical tool is effective to be applied to the teaching of Reading ESP text because there is an increase in student learning outcomes before and after the technique is applied. This research use descriptive qualitative approach. English learning Reading ESP text in the class using Translation has several advantages over other regular classes because it is supported by the implementation of good learning methods and tools.

\section{References}


[1] Marzban, A \& Azizi, A. 2011. The Role of Translation in Promoting Reading Comprehension of Iranian High School Students. Procedia Social and Behavioral Sciences 18 (2011) 526-532.

[2] Pouya, F. 2012. On The Effect of Translation on Promoting Reading Comprehension in ESP. Journal of Basic and Applied Scientific Research www.textroad.com. J. Basic. Appl. Sci. Res., Vol. 2(7)6495-6502, 2012 @ 2012, TextRoad Publication ISSN 20904304.

[3] Calis, E. \& Dikilitas, K. 2012. The use of translation in EFL classes as L2 learning practice. Procedia - Social and Behavioral Sciences 46 ( 2012 ) 5079 - 5084.

[4] Arffman, Inga. 2010. Equivalence of Translations in International Reading Literacy Studies. Scandinavian Journal of Educational Research Vol. 54, No. 1, February 2010, 37-59.

[5] Hutchinson, T., \& Waters, A. 1987, English for Specific Purposes: A learning-centered approach. Cambridge: Cambridge University Press.Andrianova, A. 2013. A Nilufar by any other Name: The Implications of Reading Sadegh Hedayat in Translation. Translation and Literature, 22 (2013), 215-39 DOI: 10.3366/tal.2013.0114 @ Edinburgh University Press. 